\title{
The Process of Facilitating Knowledge Acquisition and Retention: An Inquiry into Magnetic Poles with Challenging Questions
}

\author{
Hasan Zühtü Okulu ${ }^{1} \&$ Ayşe Oğuz Ünver ${ }^{1}$ \\ ${ }^{1}$ Science Education Department, Faculty of Education, Mugla Sitki Kocman University, Muğla, Turkey \\ Correspondence: Hasan Zühtü Okulu, Science Education Department, Faculty of Education, Mugla Sitki Kocman \\ University, Muğla 48000, Turkey. Tel: 90-252-211-1818. E-mail: hasanokulu@mu.edu.tr
}

Received: December 1, 2017

Accepted: January 12, $2018 \quad$ Online Published: April 23, 2018

doi:10.5539/ies.v11n5p25

URL: https://doi.org/10.5539/ies.v11n5p25

\begin{abstract}
The current research is to give an example to the inquiry-based science teaching implementations for facilitating knowledge acquisition and retention in a short period of time. Thus, the aim of the research is to transfer of acquired knowledge into different situations using sequential inquiry activities, which have challenging questions for inquiry about what the magnetic pole is and how to discover it. The research was designed as a pre-experimental, one-group pre-test/post-test $(\mathrm{N}=65)$ with a retention-test. Sequential inquiry-based science activities were applied to provide a series of developmentally appropriate experiences and discussions, which concretely scaffold participant's ideas of magnetism. According to the results, the participants interpreted the magnets and magnetic poles regarding their functions. The common view of the participants was that a magnetic pole should be at the ends. This view is associated with upper-lower or internal-external surfaces for a ring magnet. Finally, with a sphere magnet, both upper-lower or internal-external surfaces have lost their functions and the inquiry begins with the question "How to find the poles of a magnet?" In that process, students get to engage and feel that they do not know something that they should know.
\end{abstract}

Keywords: magnetic pole, inquiry-based science teaching, sequential activities, retention of knowledge, challenging questions

\section{Introduction}

We have common experiences regarding the magnets and magnetic poles concepts that start to be taught from 4th grade level in science classes. During these classes, first the poles of a bar magnet are determined and then it is predicted that the poles of a horseshoe magnet are at the ends. After that, the interaction of the magnets with the other objects is emphasized and finally, magnetic attraction and repulsion between two magnets are experienced. Thus, the concepts of magnetism are tried to be acquired by using concept formation or concept assimilation (Ausubel, 2000, p. 88). In teaching, the magnets are found suitable for hands-on science practices for the purpose of providing standard instructional methods and procedures which have certain steps (Wecker, Rachel, Heran-Dörr, Waltner, Wiesner, \& Fischer, 2013). In this way, the instructors are tried to be upskilled for inquiry. However, inquiry-based science teaching is not a concept that can be oversimplified as "The children gain practical skills by doing something" or "the children discover everything by themselves" (Harlen, 2014). In contrast, Students try to understand the nature and the phenomena just like a scientist in the inquiry-based science education (IBSE). An individual activates data collection, scientific process, critical thinking, communication and independent and collaborative learning skills during the inquiry process. Nowadays, it is easy for a teacher to find an activity or an experiment which is suitable for the subject in class. Many sources offer this service to teachers as printed or digital. However, doing experiments with simple materials, implementing activities by following the instructions or step by step with the guidance of the teacher do not mean that the scientific thinking skills of the students would develop. Also, it does not mean that a hands-on activity is being carried out if the students participate in and implement activities. The critical point here is the teacher's follow-up strategies during the preparation and implementation of the activity. In any case, it should not be forgotten that an activity is just a tool that serves for the inquiries and experiences of the students. The important thing is to support inquiry with dialogues and discussions among students during the activity (Oğuz-Ünver, 2015, pp. 219-220). At any level of inquiry, the activities should have certain qualities. According to these qualities', students;

- engage in scientific-based questions, 
- prioritize evidence to find answers to his/her questions,

- create evidence-based explanations,

- $\quad$ associate his/her explanations with existing scientific knowledge,

- communicate with peers and defend his/her explanations (National Research Council [NRC], 2000, pp. 161-171).

With this point of view, studies on students' understanding of the magnetism are to be reviewed.

\subsection{What the Literature Tells Us}

Studies on students' understanding of the magnetism are likely depending on the prior knowledge of the subject matter and on the mental models about the magnetic field. The studies about magnetic properties between the ages 4-6 usually tell us a large number of children of this age discover the forces of attraction of magnets on metal objects and the forces of attraction and repulsion between magnets, while they also start to learn which substances are attracted by magnets and which are not. Moreover, children may think that magnets attract all metals or that larger magnets are stronger than the smaller ones (e.g., Piaget \& Chollet, 1973; Ravanis, 1994, 1996; Fedele, Michelini, \& Stefanel, 2005; Papadopoulou \& Poimenidou, 2008; Christidou, Hatzinikita, \& Dimitriou, 2009; Wilcox \& Richey, 2012). Children older than those ages link magnetic properties with gravitational phenomena (e.g., Selman, Krupa, Stone, \& Jacquette, 1982; Bradamante \& Michelini, 2005; Bradamante \& Viennot, 2007), a kind of electricity, pressure of air, magnetic stream, a kind of lighting, rays and heat which are concepts derived from everyday life or education (e.g., Barrow, 1987; Erickson, 1994; Bar, Zinn, \& Rubin, 1997; Bar \& Zinn, 1998; Herrmann, Hauptmann, \& Suleder, 2000; Maloney, O’kuma, Hieggelke, \& Van Heuvelen, 2001; Anderson, Lucas, \& Ginns, 2003; Ravanis, Pantidos, \& Vitoratos, 2009). Apart from those studies, there is a focus on mental representations about magnetic field (e.g., Piaget \& Chollet, 1973; Erickson, 1994; Borges, Tecnico, \& Gilbert, 1998; Ravanis, Pantidos, \& Vitoratos, 2009, 2010; Cheng \& Brown, 2015). Ravanis, Pantidos, and Vitoratos (2010) aimed to investigate students' mental representations about magnetic field in connection to the Newtonian model based on four tasks. The results of four tasks indicate that the students had difficulty in evaluating actual or hypothetical experimental situations involving the application of the properties of the magnetic field. Erickson (1994) described three models of magnetism found among nine to fourteen years old children in Canada. Additionally, the students' mental models on magnetism were pulling magnet, emanating model and enclosing model. Borges et al. (1998) identified the mental models of learners. The learners construct and use mental models to think about electric current, magnetism, and about the relationship between electricity and magnetism. Five models that are magnetism as pulling, magnetism as a cloud, magnetism as electricity, magnetism as electric polarization and field model were found. Overall, in early ages, children tend mainly to recognize the attractive effects of interactions and especially the oldest ones tend to identify magnetism as electricity and gravity. However, the studies refer largely to magnetic interactions and do not much provide any information about the nature of magnetic pole. Limited studies mentioned the students' difficulties on recognition of magnetic poles (e.g., Borges et al., 1998; Fedele et al., 2005; Wilcox \& Richey, 2012). With this understanding, the first objective of the current research is to give an example to the inquiry-based science teaching implementations which are compatible with updated science curricula. Then, followed strategies in today's school programs related to the process of facilitating knowledge acquisition and retention in a short period of time are discussed. Another aim of the research is to transfer of acquired knowledge into different situations using sequential inquiry activities which have challenging questions for inquiry about what the magnetic pole is and how to discover it.

\section{Method}

School science programs indicate students should deeply understand that magnets attract and repel each other and other materials as well as understanding magnetic poles. Studies indicated that if students are not carefully scaffolded through these concrete activities, the aforementioned misconceptions may inhibit meaningful engagement with the concept. Everyday experiences and focusing on the usage of magnets could help students gain greater insight into how magnets work.

\subsection{Research Design and Participants}

The research was designed on a pre-experimental, one-group pre-test/post-test design model. To determine the sample's retention of the knowledge, an additional retention test was carried out 3 months after the post-test. The model is presented below (see Table 1). 
Table 1. Research model

\begin{tabular}{|c|c|c|c|c|}
\hline Group & Pre-Test & Activity & Post Test & Retention Test \\
\hline $\begin{array}{l}\text { Study } \\
\text { group }\end{array}$ & $\begin{array}{l}\text {-What is/are the magnetic pole(s)? } \\
\text {-How many pole(s) do given } \\
\text { magnets (bar, horseshoe, disk, ring, } \\
\text { and sphere) have? } \\
\text { - Where is/are magnetic pole(s) of } \\
\text { given magnets (bar, horseshoe, disk, } \\
\text { ring, and sphere)? }\end{array}$ & $\begin{array}{l}\text { Implementation of } \\
\text { sequential activities }\end{array}$ & $\begin{array}{l}\text { - How many pole(s) } \\
\text { do the cube magnets } \\
\text { have? } \\
\text { - Where is/are } \\
\text { magnetic pole(s) of } \\
\text { the cube magnet? }\end{array}$ & $\begin{array}{l}\text { - What is/are the magnetic pole(s)? } \\
\text { - How many pole(s) do given magnets } \\
\text { (bar, horseshoe, disk, ring, sphere, and } \\
\text { cube) have? } \\
\text { - Where is/are magnetic pole(s) of } \\
\text { given magnets (bar, horseshoe, disk, } \\
\text { ring, sphere, and cube)? }\end{array}$ \\
\hline
\end{tabular}

The study group consisted of 65 (42 women and 23 men) third-year students attending in the Science Teaching Program of the Education Department of a University, all of whom were selected convenience sampling. Convenience sampling is advantageous in that it allows the selection of a study group that is accessible and appropriate to the aim of the research and facilitates time scheduling (Frankel, Wallen, \& Hyun, 2012, p. 100). The pre-service teachers were students in a four-year under graduate program. The participants were from different backgrounds including rural-urban regions, socioeconomic status, etc. Since the pre-service teachers would be teaching science classes at the primary school level, they would be handling the topic of magnets, nature of magnetic pole, magnetic field and magnetism and so it was the basic reason for the study to be conducted with this group. Moreover, the participants took instruction in General Physics and the General Physics Laboratory courses, where the subject of magnetism was taught.

\subsection{Description of the Study}

A pretest which is inquired the poles of the magnets was applied to the participants (Appendix A). This instrument begins with the open-ended question: What is the magnetic pole? In the following step, the participants were asked to predict the poles of a bar and a horseshoe magnet on pictures, respectively. Then, they were asked to predict poles of a disc and a ring magnet on pictures. Finally, the participants were asked to determine the poles of a given spherical magnet. The purpose here is to arouse curiosity with creating mental contradictions about what the magnetic pole is and how to find it. Subsequently, to provide a series of developmentally appropriate experiences and discussions, which concretely scaffold participants ideas of magnetism, sequential inquiry-based science activities were applied. Participants were divided into groups of 4 to 5 people. A piece of styrofoam, a small magnet and some water in a plastic container were given each group in the beginning of activities. The participants were asked to place a small magnet on the styrofoam and leave them on the water. Then, the compasses were given to the participants. The magnetic field of the Earth associates to the compass. The magnetic polarity of a bar magnet acts in this way since it is oriented with the poles of the Earth (see Figure 1).

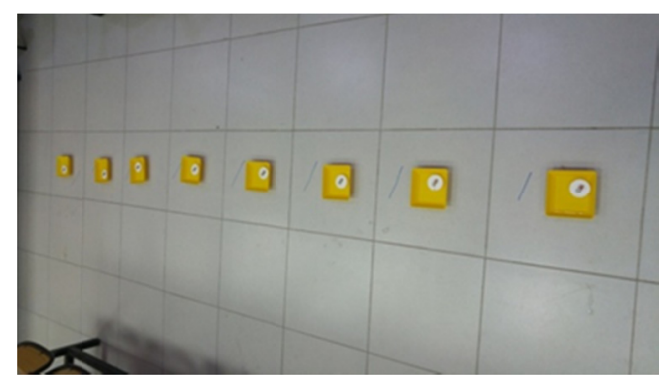

Figure 1. Magnets oriented with the poles of the Earth

In the second step, different types of magnets were covered with plain white paper. The magnets were not shown to the participants. Iron powders were poured on papers. The participants were asked to make observations by raising questions about the formed shapes (see Figure 2). The questions were "Where do they formed shapes concentrate?", "Do you have any prediction about the shapes of the magnets?", "Are there repetitive parts in the formed shapes?" and "Are there differences in the formed shapes?" 


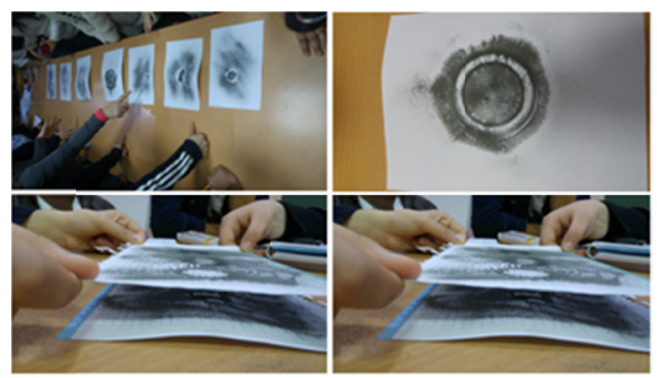

Figure 2. 2D magnetic fields of different types of magnets

In the third step, a mixture of baby oil and iron powder were put into a glass and two bar magnets were brought closer to the glass. The formed shape was observed (Figure 3) (see below). It was inquired how this phenomenon provides knowledge about the attraction forces. Then, it was asked to compare with the observations obtained in the previous experiment. Thus, the participants were acquired knowledge about the poles of magnets and the attraction areas of magnets in this step.

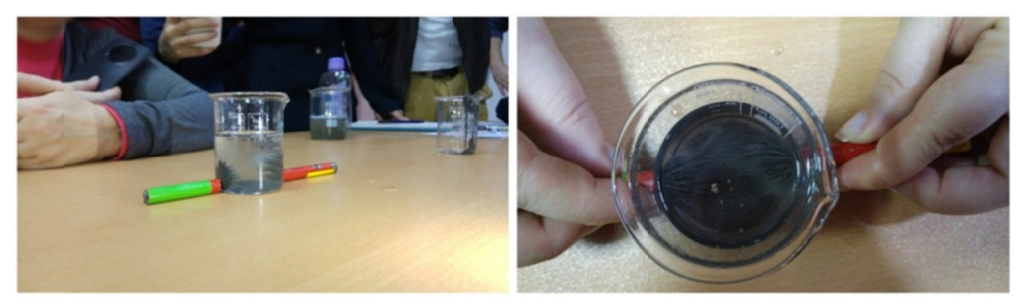

Figure 3. Magnetic influence in three dimensions

In the fourth step, the participants designed their own experiments about how to find the poles of a spherical magnet by discovering the interaction of two magnets with each other (see Figure 4).

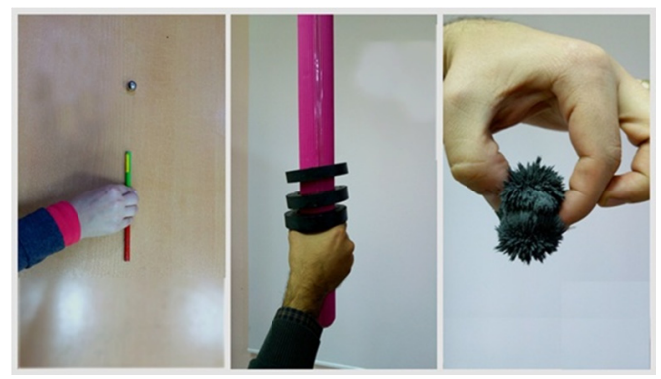

Figure 4. Finding the poles of sphere magnet

After the activities, an evaluation test was applied as a posttest. The poles of a cube magnet with many sides and surfaces were inquired in the posttest (Appendix B). The aim here is to measure whether participants are able to evaluate the poles of a magnet with a scientific point of view, independently from ends and surfaces. Finally, a retention test which includes pretest and posttest was applied after 3 months from activities (Appendix C).

\section{Results and Discussion}

The findings obtained from the research results are presented below. The concepts used by the participants $(\mathrm{N}=$ 65 ) to describe the magnetic pole in the pretest and the retention test are presented in Figure 5 and Figure 6 (see below). 


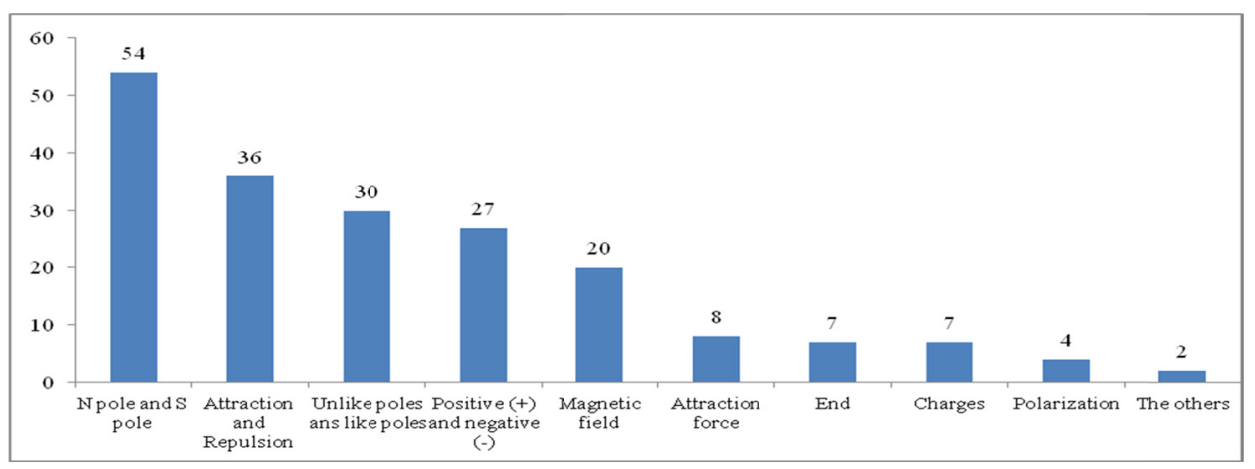

Figure 5. The Concepts used by participants to define the magnetic pole in the pretest

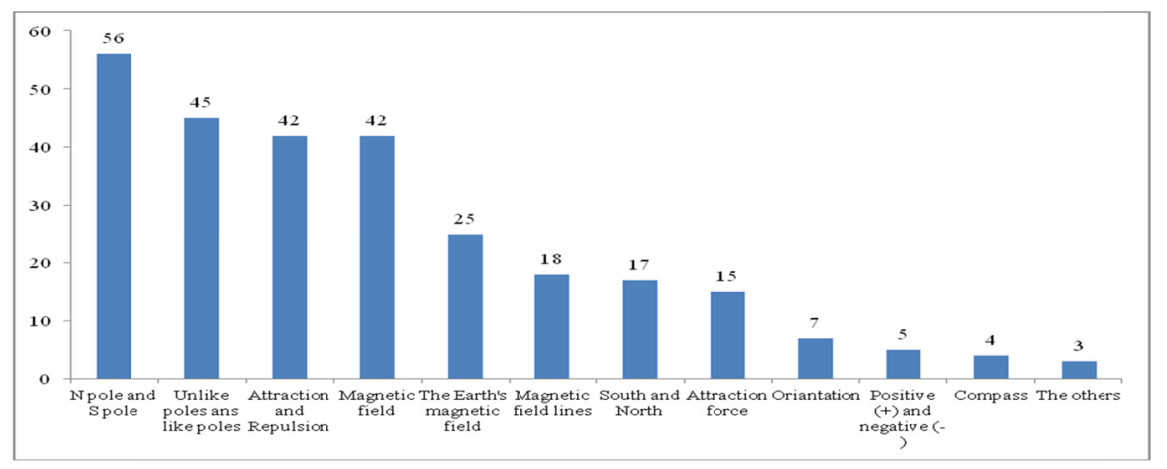

Figure 6. The Concepts used by participants to define the magnetic pole in the retention test

When Figure 5 is examined, it can be seen that the participants are used to define the concept of the magnetic pole in pretest, mostly by associating with $\mathrm{N}$ pole and $\mathrm{S}$ pole $(\mathrm{N}=54)$, attraction and repulsion $(\mathrm{N}=36)$, unlike poles and like poles $(\mathrm{N}=30)$, positive $(+)$ and negative $(-)(\mathrm{N}=27)$, and magnetic field $(\mathrm{N}=20)$. The reason of this concept diversity may probably result from overgeneralization of the magnetic phenomena. In addition, the participants' expressions include attraction force $(\mathrm{N}=8)$, end $(\mathrm{N}=7)$, charges $(\mathrm{N}=7)$, and polarization $(\mathrm{N}=4)$. The concepts such as the Earth's magnetic field and magnetic field lines have not been mentioned by participants. According to Figure 6, the definitions of participants about the magnetic pole concept in retention test frequently includes $\mathrm{N}$ pole and $\mathrm{S}$ pole $(\mathrm{N}=56)$, unlike poles, and like poles $(\mathrm{N}=45)$, attraction and repulsion $(\mathrm{N}=42)$, magnetic field $(\mathrm{N}=42)$, the Earth's magnetic field $(\mathrm{N}=25)$, north and south $(\mathrm{N}=17)$, and attraction force $(\mathrm{N}=15)$. In addition, participants have used the concepts of orientation $(\mathrm{N}=7)$, positive $(+)$ and negative $(-)(\mathrm{N}=5)$ and compass in their statements $(\mathrm{N}=4)$. Some of the participants' expressions are presented as follow; K2 in the pretest, "Magnets have two different poles. $\mathrm{N}$ is positive and $\mathrm{S}$ is negative. Since positive $(+)$ and negative (-) are opposite, they repulse each other and are accumulated at both ends. The same charges are accumulated in one place and it is the magnetic pole." $\mathrm{K} 5$ in pretest, "The magnetic pole is the phenomenon of attracting positive and negative poles.", $\mathrm{K} 4$ in the pretest, " The magnetic pole is areas in magnets which consist of $\mathrm{N}$ and S." Especially, the expressions of participants K2 and K5 indicate misusing of concepts which are not appropriate with scientific qualifications. K2 in retention test, "Magnetic pole is the area where the magnetic field lines of magnets are concentrated." K5 in retention test, "Magnets have two different poles. These poles attract or repulse each other." The expressions of K2 and $\mathrm{K} 5$ in retention test indicate that they use the correct scientific concepts while explaining the concept of the magnetic pole and they use scientific justification more in their expressions when compared with the pretest. Similarly, Borges et al. (1998) found that first-year and third-year secondary students thought that magnetic poles are regions, normally the ends of a magnet. The researchers mentioned that that may be because magnetism is related to the notion of 'two electricities' - positive and negative- which are perhaps influenced of richer technical vocabulary physics instruction. When these findings are generally evaluated, before implementation, it is seen that the concepts used by participants were limited implementation and these concepts included misconceptions such as end, charge, and positive ( + ) and negative (-). However, after the implementation, the diversity of concepts which used by the participants increased, thus the explanations of associating with different concepts enabled the 
participants to make more and deeper interpretations. The participants did not use some concepts to define magnetic pole such as the Earth's magnetic field, magnetic field lines, compass and orientation before implementation. Moreover, the concepts of end, charge, and polarization had been used before the implementation was not included in the participant expressions after the implementation. The participants used the concepts of $\mathrm{N}$ pole and S pole, like pole and unlike pole, attraction and repulsion, attraction force, and magnetic field more in their statement after implementation. Also, the misconception of positive $(+)$ and negative (-) have been used much less in the participant expressions after the implementation. This is an indication that the frequency of use of misconceptions associated with the magnetic pole was reduced and the used concepts were oriented towards the basic concepts of magnetism. The pretest results of the participants $(\mathrm{N}=65)$ on the number of poles and their location are presented in Table 2 (see below).

Table 2. The pretest results of the participants on the number of poles and their location

\begin{tabular}{|c|c|c|c|c|c|c|}
\hline & & \multicolumn{5}{|c|}{ Shape of Magnet } \\
\hline & & Bar & Horseshoe & Disc & Ring & Sphere \\
\hline \multirow{8}{*}{ The numbers of poles } & Unspecified & - & - & 5 & 10 & 18 \\
\hline & None & - & - & 2 & 1 & 2 \\
\hline & Single & - & 6 & 22 & 19 & 8 \\
\hline & Two & $64 *$ & $55^{*}$ & $34 *$ & $32 *$ & $28 *$ \\
\hline & Three & - & 3 & 1 & 1 & 1 \\
\hline & Four & 1 & 1 & 1 & 2 & 1 \\
\hline & Six & - & - & - & - & 4 \\
\hline & Total & 65 & 65 & 65 & 65 & 65 \\
\hline \multirow{12}{*}{ The location of poles } & Unspecified & 1 & 2 & 27 & 26 & 21 \\
\hline & None & - & - & 1 & - & 2 \\
\hline & Ends & $62 *$ & $53^{*}$ & - & - & - \\
\hline & Two halves & 2 & 2 & 5 & 5 & 6 \\
\hline & Everywhere & - & 5 & 1 & 4 & 3 \\
\hline & At the two ends and in the center of the oval & - & 3 & - & - & - \\
\hline & Two farthest points to the center & - & - & 1 & 1 & $17 *$ \\
\hline & On the surface & - & - & 2 & 3 & 1 \\
\hline & Upper and lower & - & - & $23^{*}$ & 7 & - \\
\hline & Internal and external & - & - & - & $17^{*}$ & 4 \\
\hline & The others & - & - & 5 & 2 & 11 \\
\hline & Total & 65 & 65 & 65 & 65 & 65 \\
\hline
\end{tabular}

Note. *: Correct answer.

According to Table 2, the findings reveal that the participants tried to find the numbers of poles and the locations of the poles associated with the shapes of the magnets before implementation. The participants used the end variable to determine the poles of bar and horseshoe magnets. However, since the disc and ring magnets do not have ends, the participants tried to determine the locations of the poles using only surface variables for these two magnets. These variables are completely absent for the sphere magnet. Especially, when they tried to find poles without end variable, the participants' answers were varied or they were not able to determine the numbers of poles and locations of poles. Similarly, Wilcox, and Richey (2012) gave students three different magnets: a bar magnet, a horseshoe magnet, and a disc magnet so that students could observe all magnets had two poles, even if the shape and size were different. However, in this case, students may still correlate the poles with the side, point, end, or surface. The underlying reason for this situation may be that the concept of the magnetic pole is taught to the students through the single variable (end concept) in teaching processes. When more than one variable is included in the process, the students are having problems in transferring the existing knowledge to the new situation. Fedele et al. (2005) observed that students have difficulties in recognition of magnetic poles. It is more problematic recognize that each pole interacts differently with another magnet and in the same way with other objects. This problem can be overcome by the operative exploration of different situations, showing the interactions like the action of couples of forces and the interaction intensity varying with distance. Correspondingly, Borges et al. (1998) defined that people holding the idea that magnets attract some materials because it is part of their nature do not acknowledge the existing of poles in the magnet. So far it can be concluded that participants' explanations for 
the magnet's behavior are frequently shallow. They could say that atoms or molecules are arranged according to special pattern and this internal order brings about magnetism yet no one attempted to explain how magnetism could originate from such a regular arrangement of atoms. The posttest and retention test results of the participants $(\mathrm{N}=65)$ on the number of poles and their location about the cube magnet are presented in Table 3 (see below).

Table 3. The posttest and retention test results of the participants on the number of poles and their location about the cube magnet

\begin{tabular}{llcc}
\hline & & Posttest & Retention test \\
\hline & Unspecified & - & - \\
& None & - & - \\
& Single & - & - \\
& Two & $55^{*}$ & $54^{*}$ \\
The numbers of poles & Three & - & - \\
& Four & 6 & 7 \\
& Six & 4 & 4 \\
& Infinite & - & - \\
& Total & 65 & 65 \\
\cline { 2 - 4 } & Unspecified & 65 & 3 \\
& On each side & 4 & 2 \\
& Two opposite side areas of the cube & $53^{*}$ & $52^{*}$ \\
& At upper and lower midpoints & 2 & 2 \\
& Four opposite side areas of the cube & 3 & 6 \\
& Total & 65 & 65 \\
\hline
\end{tabular}

Note. *: Correct answer.

An examination of Table 3 shows that, after implementation, the number of poles of the cube magnet and the locations of the poles are determined in accordance with the nature of the magnetic field without focusing on the end variable. The sequential activities aim to teach magnetism with different variables and pole concept using experiment and observation process without focusing on the end variable, made more effective adapting the knowledge to a new situation. The answers of the participants $(\mathrm{N}=65)$ related to the numbers of poles and the location of poles about the given magnets in retention test are presented in Table 4. 
Table 4. The answers of the participants related to the numbers of poles and the location of poles about the given magnets in retention test

\begin{tabular}{|c|c|c|c|c|c|c|}
\hline & & \multicolumn{5}{|c|}{ Shape of Magnet } \\
\hline & & Bar & Horseshoe & Disc & Ring & Sphere \\
\hline \multirow{7}{*}{ The numbers of poles } & Unspecified & - & - & 4 & 3 & 4 \\
\hline & None & - & - & 2 & & \\
\hline & Single & & 2 & 4 & 4 & 3 \\
\hline & Two & $65^{*}$ & $61^{*}$ & $54 *$ & $56^{*}$ & $58^{*}$ \\
\hline & Three & - & 1 & - & - & - \\
\hline & Four & - & 1 & 1 & 2 & \\
\hline & Total & 65 & 65 & 65 & 65 & 65 \\
\hline \multirow{11}{*}{ The location of poles } & Unspecified & & & 6 & 5 & 2 \\
\hline & Ends & $62 *$ & $61 *$ & - & - & - \\
\hline & Two halves & 2 & 2 & 4 & 1 & 2 \\
\hline & Everywhere & 1 & 1 & 1 & - & - \\
\hline & At the two ends and in the center of the oval & - & 1 & - & - & - \\
\hline & Two farthest points to the center & - & - & - & - & $58^{*}$ \\
\hline & On the surface & - & - & 1 & - & 1 \\
\hline & Upper and lower & - & - & $53 *$ & 1 & 2 \\
\hline & Internal and external & - & - & - & $55^{*}$ & - \\
\hline & The others & - & - & - & 3 & - \\
\hline & Total & 65 & 65 & 65 & 65 & 65 \\
\hline
\end{tabular}

Note. *: Correct answer.

According to Table 4, these findings are an indication of the participants' retention test that they are based on scientific knowledge while determining and poles of the magnets and their positions. These findings indicated that the participants think of scientific knowledge while determining the numbers of poles and their locations. In the retention test, the correct answers are the majority. The describing of a concept according to its nature is very important in terms of the transfer of knowledge and facilitating retention of knowledge. The inquiry-based and multivariable-based activities designed for any concept directly affect the retention of knowledge. Ausubel (2000) noted that the well-organized practices increase the stability and clarity of the concepts and facilitate the learning and retention of the concepts. In addition, when the instruments were examined, the participants emphasized that different pole determining techniques should be used for exact location of poles, even if they determined poles correctly. The participants desired to test and circumstantiate their ideas which are based on prediction or inference. It overlaps with nature of the inquiry. In the light of research data the frequency values of correct answers for the number of poles and their locations in different magnets in pretest and retention test are presented in Figure 7 Figure 8, respectively. Figure 9 shows that the frequency values of correct answers related to the numbers of poles and their locations on cube magnet in posttest and retention test.

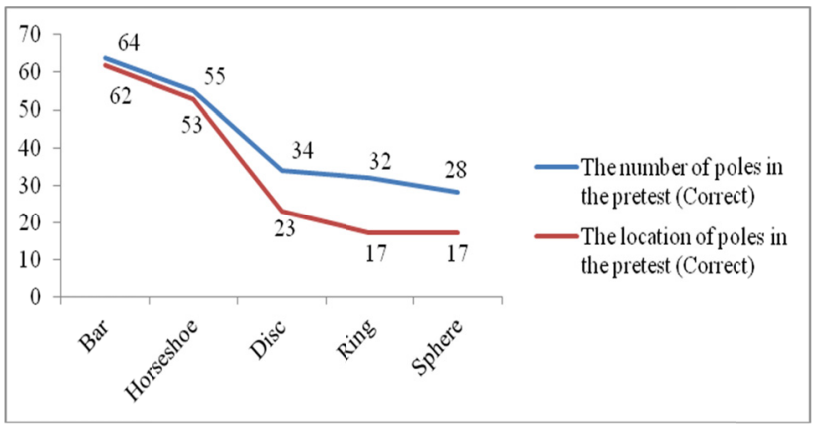

Figure 7. The frequency of correct answers for the number of poles and their locations about the different magnets in pretest 


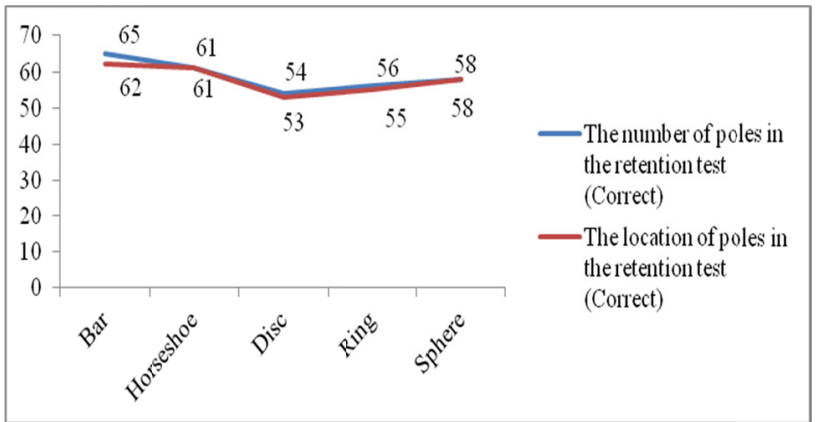

Figure 8 . The frequency of correct answers for the number of poles and their locations about the different magnets in retention test

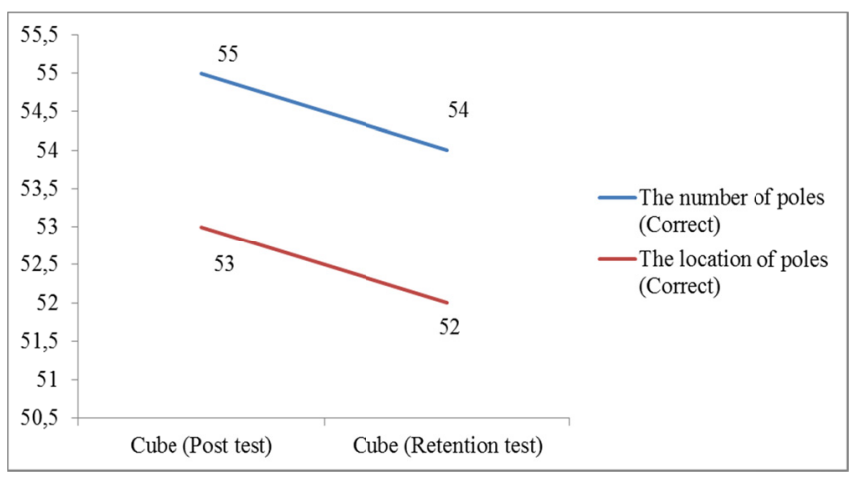

Figure 9. The frequency of correct answers for the number of poles and their locations about the cube magnet in posttest and retention test

Figure 7 shows that there was no contradiction in the number of poles and their locations on bar magnet and horseshoe magnet in the pretest. The correct answers for the number of poles were fewer in the other types of magnets (disk, ring, and sphere). Besides, the correct answer frequency was further decreased for determining the poles of the magnets. The acquired knowledge (assumed to be taught) has not been transferred to different situations and learning has not been achieved sufficiently. This data may be considered as proof that the learning practices still base on memorization at schools. When Figure 8 and Figure 9 are examined, it is seen that the activities based on inquiry-based science teaching has increased the correct answers of the students and it is consistent even in the retention test which applied after 3 months from implementation. When the findings of the study are evaluated in general, one of the most important findings is confirmation of a Piaget's (1963) claim once again: "The objects take their meanings from their actions." According to pre-test results, the participants interpreted the magnets and magnetic poles through their functions. The general opinion for the participants is that a magnetic pole should be at the ends. This opinion is associated with upper-lower or internal-external surfaces for a ring magnet. Finally, with a sphere magnet, both upper-lower or internal-external surfaces have lost its functions and the inquiry begins with the question "How to find the poles of a magnet?". In that process, students get to engage and feel that they don't know something that they should know.

\section{Conclusion}

This study has a number of educational implications. First, this research attempted to show how to support inquiry with the challenging questions, which are created in the students' minds using multiple variables instead of a single variable during the teaching process. In this way, the retention of knowledge, which is gained in a short period of time such as a course hour, has brought the student to a higher level of knowledge which is used inquiry instead of memorizing about magnetism. The inquiry is the transfer of science concepts without removing scientific thought. In this research, challenging questions were asked for engaging students to test their understanding. Effective questioning also helps researchers to diagnose students' pre-knowledge and scaffolding students toward to maximize their learning. Second, our finding indicates that although students can speak of magnetic poles, they do not have a fully developed notion of what the magnetic poles are. Many of them face difficulties in explaining the 
magnetic poles of different shapes of magnets besides bar and horseshoe. Organizing the appropriate teaching activities in order to make the properties of the magnetic poles better understood, as well as the question of reorganizing sections of the curriculum in order to study magnetic properties to become systematically linked to questions of the general properties and the nature of poles. Students have difficulties in understanding the course subjects that are too abstract. The solution usually seems to memorization of the key facts, but unfortunately it never mentally engage with the students with the concepts. Students interpret classroom activities through the lens of their prior experiences. As a result, one activity is not enough to adequately challenge students' misconceptions. It appears that a discussion concerning a satisfactory comprehension of the magnetic poles has to encompass not only the ordinary kinds of the magnets like bar and horseshoe but also the special applications of these properties in various experimental situations. Finally, predictions can be a powerful formative assessment tool for the teacher when students have substantial background information with the phenomena. If the students do not have an adequate knowledge to make logical predictions based on evidence, students often end up just guessing. In this study since the students have numerous prior experiences with magnets, their predictions help researchers to establish their level of understanding.

\section{References}

Anderson, D., Lucas, K. B., \& Ginns, I. S. (2003). Theoretical perspectives on learning in an informal setting. Journal of Research in Science Teaching, 40(2), 177-199. https://doi.org/10.1002/tea.10071

Ausubel, D. P. (2000). The acquisition and retention of knowledge: A cognitive view. Dordrecht: Springer. https://doi.org/10.1007/978-94-015-9454-7

Bar, V., \& Zinn, B. (1998). Similar frameworks of action-at-a-distance: Early scientists' and pupils' ideas. Science \& Education, 7(5), 471-491. https://doi.org/10.1023/A:1008687204309

Bar, V., Zinn, B., \& Rubin, E. (1997). Children's ideas about action at a distance. International Journal of Science Education, 19(10), 1137-1157. https://doi.org/10.1080/0950069970191003

Barrow, L. H. (1997). Magnet concepts and elementary students' misconceptions. In J. Novak (Ed.), Proceedings of the Second International Seminar, Misconceptions and Educational Strategies in Science and Mathematics (pp. 16-22). Retrieved from ERIC database. (ED242553)

Borges, A. T., Tecnico, C., \& Gilbert, J. K. (1998). Models of magnetism. International Journal of Science Education, 20(3), 361-378. https://doi.org/10.1080/0950069980200308

Bradamante, F., \& Michelini, M. (2005, August). Exploring children's spontaneous ideas of magnetic and gravitational fields hands-on exhibits. Paper presented at the European Science Education Research Association (ESERA) Conference, Barcelona.

Bradamante, F., \& Viennot, L. (2007). Mapping gravitational and magnetic fields with children 9-11: Relevance, difficulties and prospects. International Journal of Science Education, 29(3), 349-372. https://doi.org/10.1080/09500690600718245

Cheng, M. F., \& Brown, D. E. (2015). The role of scientific modeling criteria in advancing students' explanatory ideas of magnetism. Journal of Research in Science Teaching, 52(8), 1053-1081. https://doi.org/10.1002/tea.21234

Christidou, V., Hatzinikita, V., \& Dimitriou, A. (2009). Children's drawings about environmental phenomena: The use of visual codes. International Journal of Science in Society, 1(1), 107-117.

Erickson, G. (1994). Pupils' understanding of magnetism in a practical assessment context: the relationship between content, process and progression. In P. J. Fensham, R. F. Gunstone, \& R. T. White (Eds.), The content of science: A constructivist approach to its teaching and learning (pp. 80-97). Washington: The Falmer Press.

Fedele, B., Michelini, M., \& Stefanel, A. (2005, August). Five-ten years old pupils explore magnetic phenomena in Cognitive Laboratory (CLOE). Paper presented at the European Science Education Research Association (ESERA) Conference, Barcelona.

Fraenkel, J. R., Wallen, N. E., \& Hyun, H. H. (2012). How to design and evaluate research in education (8th ed.). New York: McGraw-Hill.

Harlen, W. (2014). Helping children's development of inquiry skills. Inquiry in Primary Science Education, 1(1), 5-19.

Herrmann, F., Hauptmann, H., \& Suleder, M. (2000). Representations of electric and magnetic fields. American Journal of Physics, 68(2), 171-174. https://doi.org/10.1119/1.19391 
Landis, J. R., \& Koch, G. G. (1977). An application of hierarchical kappa-type statistics in the assessment of majority agreement among multiple observers. Biometrics, 33(2), 363-374. https://doi.org/10.2307/2529786

Maloney, D. P., O’Kuma, T. L., Hieggelke, C. J., \& Van Heuvelen, A. (2001). Surveying students' conceptual knowledge of electricity and magnetism. American Journal of Physics, 69(7), 12-23. https://doi.org/10.1119/1.1371296

National Research Council. (2000). Inquiry and the National Standards: A Guide for Teaching and Learning. Washington, DC: National Academy Press.

Oğuz-Ünver, A. (2015). Bilimin doğası ve bilimsel sorgulama ilişkisi. In N. Yenice (Ed.), Bilimin doğası, gelişimi ve öğretimi (pp. 218-255). Ankara: Anı.

Papadopoulou, M., \& Poimenidou, M. (2008). The contribution of play in the emergence of hybrid genres in kindergarten. In N. Nørgaard (Ed.), Systemic functional linguistics in use. Odense Working Papers in Language and Communication, 29, 621-632.

Piaget, J. (1963). The Psychology of Intelligence. Totowa, New Jersey: Littlefield Adams.

Piaget, J., \& Chollet, M. (1973). Le problème de l'attraction à propos des aimants. In J. Piaget (Ed.), La formation de la notion de force (pp. 223-243). Paris: PUF.

Ravanis, K. (1994). The discovery of elementary magnetic properties in preschool age: qualitative and quantitative research within a Piagetian framework. European Early Childhood Education Research Journal, 2(2), 79-91. https://doi.org/10.1080/13502939485207621

Ravanis, K. (1996). Stratégies d'interventions didactiques pour l'initiation des enfants de l'école maternelle en sciences physiques. Spirale, 17, 161-176. https://doi.org/10.3406/spira.1996.1924

Ravanis, K., Pantidos, P., \& Vitoratos, E. (2009). Magnetic field mental representations of 14-15 years old students. Acta Didactica Napocensia, 2(2), 1-8.

Ravanis, K., Pantidos, P., \& Vitoratos, E. (2010). Mental Representations of ninth grade students: The case of the properties magnetic field. Journal of Baltic Science Education, 9(1), 50-60.

Richards, T. (2002). An intellectual history of NUD* IST and NVivo. International Journal of Social Research Methodology, 5(3), 199-214. https://doi.org/10.1080/13645570210146267

Selman, R. L., Krupa, M. P., Stone, C. P., \& Jacquette, D. S. (1982). Concrete operational thought and the emergence of the concept of unseen force in children's theories of electromagnetism and gravity. Science Education, 66(2), 181-194. http://dx.doi.org/10.1002/sce.3730660205

Wecker, C., Rachel, A., Heran-Dörr, E., Waltner, C., Wiesner, H., \& Fischer, F. (2013). Presenting theoretical ideas prior to inquiry activities fosters theory-level knowledge. Journal of Research in Science Teaching, 50(10), 1180-1206. https://doi.org/10.1002/tea.21106

Wilcox, J., \& Richey, L. R. (2012). May the magnetic force be with you: Using concrete activities to confront misconceptions about magnetism in the primary grades. Science and Children, 50(2), 62-67.

\section{Appendix A}

\section{Worksheet 1: Pre Activity}

Name-Surname:

Date:

1) What is/are the magnetic pole(s)?

2) Please specify your predictions about the pole(s) of the given magnet. Mark the pole(s) of the magnet.

\begin{tabular}{|c|c|c|}
\hline Magnet & $\begin{array}{c}\text { How many pole(s) does the } \\
\text { given magnet has? }\end{array}$ & $\begin{array}{c}\text { Where is/are magnetic } \\
\text { pole(s) of the given magnet? }\end{array}$ \\
\hline & & \\
& & \\
\hline
\end{tabular}




\begin{tabular}{|l|l|l|}
\hline & & \\
\hline
\end{tabular}

\section{Appendix B}

\section{Worksheet 2: Post Activity (Evaluation)}

Name-Surname:

Date:

1) Can you predict the pole(s) of the given magnet after the activity? Mark the pole(s) of the cube magnet.

\begin{tabular}{|c|c|c|}
\hline Magnet & $\begin{array}{c}\text { How many pole(s) does the } \\
\text { given magnet has? }\end{array}$ & $\begin{array}{c}\text { Where is/are magnetic pole(s) } \\
\text { of the given magnet? }\end{array}$ \\
\hline & & \\
\hline
\end{tabular}

\section{Appendix C}

\section{Worksheet 3: Post Activity (Retention)}

Name-Surname:

Date:

1) What is/are the magnetic pole(s)?

2) Please specify your predictions about the pole(s) of the given magnet. Mark the pole(s) of the magnet. 


\begin{tabular}{|l|l|l|}
\hline Magnet & $\begin{array}{c}\text { How many pole(s) does the } \\
\text { given magnet has? }\end{array}$ & $\begin{array}{c}\text { Where is/are magnetic } \\
\text { pole(s) of the given magnet? }\end{array}$ \\
\hline & & \\
\hline & & \\
\hline
\end{tabular}

\section{Copyrights}

Copyright for this article is retained by the author(s), with first publication rights granted to the journal.

This is an open-access article distributed under the terms and conditions of the Creative Commons Attribution license (http://creativecommons.org/licenses/by/4.0/). 